\title{
Implementing the Risk of Ovarian Malignancy Algorithm Adding Obesity as a Predictive Factor
}

\author{
EMANUELA ANASTASI ${ }^{1}$, DANILA CAPOCCIA ${ }^{2}$, TERESA GRANATO ${ }^{3}$, \\ GIANFRANCO SILECCHIA ${ }^{4}$, MARIO RIZZELLO ${ }^{4}$, MARIA GRAZIA PORPORA ${ }^{5}$, \\ LUIGI FRATI ${ }^{1}$, ANTONIO ANGELONI ${ }^{1}$ and FRIDA LEONETTI ${ }^{2}$ \\ Departments of ${ }^{1}$ Molecular Medicine, ${ }^{2}$ Experimental Medicine and \\ ${ }^{5}$ Gynaecology, Obstetrics and Urology, Policlinico Umberto I, Sapienza University of Rome, Rome, Italy; \\ ${ }^{3}$ CNR-IBPM, National Research Council, Rome, Italy; \\ ${ }^{4}$ Department of Medico-Surgical Sciences and Biotechnologies, \\ Bariatric Center of Excellence IFSO EU, Sapienza University of Rome, Latina, Italy
}

\begin{abstract}
Aim: To evaluate whether obesity represents a risk factor for the onset of ovarian cancer. Patients and Methods: One hundred and sixty-three patients with a body mass index $(B M I)>30 \mathrm{~kg} / \mathrm{m}^{2}$ (group 1) and 130 women with a BMI of $<25 \mathrm{~kg} / \mathrm{m}^{2}$ (group 2) were included in the study. Results: A Risk of Ovarian Malignancy Algorithm (ROMA) index above the cut-off (>13\%) was found in $24.5 \%$ of group 1 patients, whereas a high ROMA score was identified in $5.3 \%$ of group 2 women. During the study, 13 out of 40 group 1 patients with ROMA $>13 \%$ were deemed eligible for bariatric surgery. After bariatric surgery and decrease of BMI, eight out of these 13 obese women had a ROMA index $<13 \%$. Conclusion: The ROMA index may function as a simple test able to screen obese women at risk of developing ovarian cancer.
\end{abstract}

Ovarian cancer (OC) is an aggressive tumor associated with a high mortality and morbidity (1). Due to the lack of early symptoms, as well as of early diagnostic tools, this disease is usually diagnosed at a late stage (2). The overall worldwide OC incidence is 204,499 cases per year with a mortality of 124,860 patients per year (3). Currently, a combination of physical examination and serum biomarker measurement are the first step in the diagnostic process. The role of tumor markers in the diagnosis and monitoring of OC is well established (4). The current benchmark biomarker for

Correspondence to: Emanuela Anastasi, Department of Molecular Medicine, University "Sapienza", Viale Regina Elena 324, 00161 Rome, Italy. Tel: +39 064472347, Fax: +39 064478381, e-mail: emanuela.anastasi@uniroma1.it

Key Words: Obesity, ovarian cancer, CA125, HE4, ROMA index, insulin, bariatric surgery. ovarian cancer is cancer antigen 125 (CA125). This tumor marker was originally identified following the development of the OC125 antibody that binds the celomic epithelial antigen produced by mesothelial cells lining the peritoneal, pleural and pericardial cavities (3-6). CA125 is usually part of the initial assessment of a pelvic mass and is used to monitor response to chemotherapy, as well as to detect refractory or relapsing disease after an initial response to treatment $(7,8)$.

More recently, human epididymis protein 4 (HE4) has been proposed as an emerging biomarker in OC differential diagnosis. This marker has been shown to be a good tool for the differential diagnosis of a pelvic mass as it particularly has a higher specificity compared to CA125 in discriminating epithelial ovarian cancer (EOC) from benign disease $(9,10)$. It is also more specific and sensitive in detecting EOC at an early stage. It can be used for monitoring response to chemotherapy and for estimating the prognosis of EOC $(11,12)$. HE4 was incorporated into two disease evaluation formulas known as the Risk of Malignancy Algorithm (ROMA), this algorithm has been developed for both pre-and postmenopausal women. ROMA combines the diagnostic power of the CA125 and HE4 markers with menopausal status without requiring imaging evaluation. This algorithm has been accepted by the US Food and Drug Administration for differentiating malignant from benign pelvic masses (13). ROMA performs better in the premenopausal population than in postmenopausal women. Women are stratified by a predicted probability (PP), a PP higher than $13.1 \%$ indicates a high risk in the premenopausal population and a value higher than $27.7 \%$ indicates a high risk in the postmenopausal population (14).

Diet-related factors such as a high content of starch and fat have been shown to be associated with an increase of ovarian carcinoma risk (15). On the other hand, a slight 
decrease in risk seems to be associated with a diet rich in fiber, carotene, vitamins C, E and D, and unsaturated fatty acids (16-18). Obesity has been shown to be an established risk factor for many hormone-related types of cancer such as breast, colon, endometrial and prostate carcinoma (19).

We aimed to evaluate whether obesity as a disease itself could represent a risk factor for the onset of EOC. Specifically, our objective was to demonstrate if obesity increased the predictive power of ROMA. We selected a population of obese (group 1) and non-obese (group 2) premenopausal women in order to exclude menopausal status as a confounding factor.

\section{Patients and Methods}

Patients. Body mass index (BMI) categories were defined by the National Institutes of Health's: underweight: BMI $<18.5 \mathrm{~kg} / \mathrm{m}^{2}$; ideal body weight: $\mathrm{BMI}=18.5$ to $25 \mathrm{~kg} / \mathrm{m}^{2}$; overweight: 25 $\leq$ BMI $\leq 30 \mathrm{~kg} / \mathrm{m}^{2}$; and obese: $>30 \mathrm{~kg} / \mathrm{m}^{2}(11)$.

Group 1 comprised 163 patients from the Obesity Center at the Policlinico Umberto I, with a BMI $>30 \mathrm{~kg} / \mathrm{m}^{2}$ (mean age $=34$ years, range $=23-45$ years). Group 2 was 132 women from the Gynaecology Department at the Policlinico Umberto I in Rome. These patients, unlike group 1 , had a BMI of $<25 \mathrm{~kg} / \mathrm{m}^{2}$ and were therefore classified as normal-weight (mean age $=36$ years, range $=21-47$ years). All women underwent abdominal and transvaginal ultrasound with color Doppler to exclude ovarian masses.

Co-morbidities were also examined, including type 2 diabetes, hypertension, obstructive sleep apnea syndrome (OSAS) and dyslipidemia. Comorbidities are listed in Table I.

All serum samples were collected at the time of the first medical examination before the administration of any therapy.

CA125 determination. The automated chemiluminescent enzyme immunoassay (CLEIA) system Lumipulse ${ }^{\circledR}$ G1200 CA125II is an assay system for quantitative CA125 measurement in specimens based on CLEIA technology by a two-step sandwich method (Fujirebio Inc, Tokyo, Japan). This assay utilizes a solid-phase and alkaline phosphatase (ALP)-labeled monoclonal antibodies (OC125 and M11, respectively). CA125 in specimens specifically bind to the monoclonal antibody to CA125 immobilized on the particles, forming antigen-antibody immunocomplexes. Particles are then washed and rinsed in order to remove unbound materials. ALPlabeled anti-CA125 monoclonal antibody specifically binds to CA125 of the immunocomplexes. After a second wash, substrate solution is added. Adamantyl-1,2-dioxetane phosphate (AMPPD) contained in the substrate solution is dephosporylated by the catalysis of ALP indirectly conjugated to the particles. A luminescent signal is generated by the cleavage reaction of dephosphorylated AMPPD and reflects the amount of CA125 in the sample. According to the manufacturer, the normal cut-off level for CA125 is $<35 \mathrm{U} / \mathrm{ml}$.

HE4 determination. HE4 levels were determined using the HE4 EIA assay (Fujirebio Diagnostics AB, Goteborg, Sweden). The HE4 EIA is a solid-phase, noncompetitive immunoassay based upon the direct sandwich technique using two monoclonal antibodies, 2H5 and
3D8, directed against two epitopes in the C-WFDC domain of HE4. Control or patient serum samples and standards were incubated with biotinylated anti-HE4 monoclonal antibody $2 \mathrm{H} 5$ aliquots in streptavidin-coated microstrips. HE4 present in standards or serum samples were adsorbed to the streptavidin-coated microstrips by the biotinylated anti-HE4 monoclonal antibody during the incubation period. The strips were then washed and incubated with HRPlabeled anti-HE4 monoclonal antibody 3D8. After washing, buffered substrate/chromogen reagent was added to each well, and the enzyme reaction was allowed to proceed. During the enzyme reaction, a blue color developed if the antigen was present. Color intensity was directly proportional to the amount of HE4 present in the samples.

ROMA index. ROMA was calculated as per the HE4 package insert. For premenopausal women it is defined as follows: predictive index $(\mathrm{PI})=-12.0+2.38 \times \operatorname{Ln}[\mathrm{HE} 4]+0.0626 \times \operatorname{Ln}[\mathrm{CA} 125]$. For postmenopausal women, it is defined as follows: $\mathrm{PI}=-8.09+1.04 \times \mathrm{Ln}[\mathrm{HE} 4]$ $+0.732 \times \operatorname{Ln}[\mathrm{CA} 125]$, where Ln stands for natural log. ROMA was calculated from the PI as follows: ROMA $=\exp (\mathrm{PI}) /[1+\exp (\mathrm{PI})] \times 100$. A value greater than $13.1 \%$ suggests a high risk in premenopausal women.

Insulin determination. Insulin levels were detected using the Lumipulse ${ }^{\circledR}$ G1200 system (Fujirebio Inc, Tokyo, Japan). This is for the quantitative measurement of insulin in specimens based on CLEIA technology by a one-step immunoassay method. According to the manufacturer, the normal cut-off level for insulin is $2.2-15.7 \mu \mathrm{IU} / \mathrm{ml}$.

Statistical analysis. The statistical significance of differences in ROMA index between obese woman and normal-weight woman was assessed using a Chi-square test for categorical variables. Correlation between insulin and tumor markers was investigated using Pearson correlation test. All statistical analysis were carried out using MedCalc V 4.30 Software, Italy.

\section{Results}

Definition of normal levels in our normal weight women: HE4. One hundred and thirty normal weight women were included in this study (group 2). These samples were evaluated thanks to a collaboration with the Department of Gynecology of the Policlinico Umberto I in Rome. On the basis of these results, we considered a value of $79.5 \mathrm{pmol} / 1$ HE4 (=mean $\pm 2 \mathrm{SD}=49.53 \pm 15 \mathrm{pmol} / \mathrm{l})$ as the cut-off.

Biomarker distribution in obese and non-obese women. HE4 levels above the cut-off value were detected in $8.6 \%$ (14/163) of group 1. High serum HE4 levels were detected only in $3 \%$ (4/130) of the normal-weight women (group 2). The difference between the two percentages was statistically significant $(p<0.007)$. With regards to CA125, levels above the cut-off value were observed in $2.5 \%$ (4/163) of group 1 and in $6.1 \%(8 / 130)$ of group 2 . The difference between the two percentages was statistically significant $(p<0.004)$. The ROMA index was investigated in obese women in comparison with normal-weight women. ROMA score above 
Table I. Prevalence of comorbidities in obese women of this study.

\begin{tabular}{lc}
\hline Comorbidity & Prevalence \\
\hline Type 2 diabetes & $33.7 \%(55 / 163)$ \\
OSAS & $31.9 \%(52 / 163)$ \\
Hypertension & $25.7 \%(42 / 163)$ \\
Dyslipidemia & $8.4 \%(30 / 163)$ \\
\hline
\end{tabular}

Table II. Clinical characteristics of obese women pre and post bariatric surgery $(n=13)$.

\begin{tabular}{lcc}
\hline & Pre bariatric surgery & Post bariatric surgery \\
\hline Weight $(\mathrm{kg})$ & $115.4 \pm 18$ & $88.4 \pm 10$ \\
BMI $\left(\mathrm{kg} / \mathrm{m}^{2}\right)$ & $42.4 \pm 7.8$ & $32.5 \pm 7.2$ \\
Insulin $(\mu \mathrm{U} / \mathrm{ml})$ & $34.1 \pm 1.2$ & $15.2 \pm 0.7$ \\
\hline
\end{tabular}

the cut-off (>13\%) was detected in $24.5 \%$ (40/163) of group 1 , whereas in group 2, a high ROMA score was identified only in $5.3 \%(7 / 130)$ of the women $(p<0.009)$.

Basal insulin values in obese and non-obese women. In the present study, we combined, for obese women, the values of HE4 with basal circulating insulin levels. The data obtained demonstrate that levels of HE4 only weakly positively correlated with levels of insulin $(\mathrm{r}=0.16 ; p$-value $=0.064$; Figure 1). However, no correlation was observed with CA125.

We investigated the relationship between levels of basal insulin and ROMA index in obese woman (group 1). The, $37 \%$ of obese women with ROMA index $>13 \%$ had a concomitant high level of insulin, while only $24 \%$ of obese women with ROMA index $<13 \%$ had high levels of insulin $(p<0.001)$. Therefore, the insulin level was significantly higher in obese women with ROMA $>13 \%$.

During the study, 13 out of 40 group 1 patients with ROMA $>13 \%$ were deemed eligible for bariatric surgery. After bariatric surgery and decrease of BMI, we observed that the insulin levels were within the normal range (Table II). In addition, 8 out of 13 showed the ROMA index below $13 \%$.

\section{Discussion}

Obesity is an established risk and progression factor for many types of cancer, in particular there is rising evidence for a relationship between obesity and higher risk of OC, advanced prostate cancer, and hepatocellular carcinoma (20). The correlation between EOC and obesity is still under discussion; studies describe an increased risk by $30 \%$ in obese woman compared to woman with a BMI in the 'healthy' range $(21,22)$.

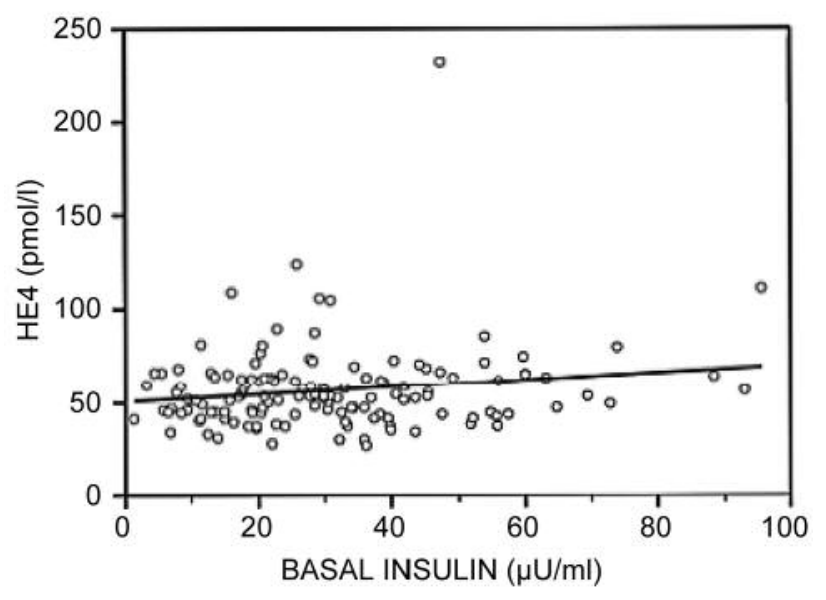

Figure 1. Correlation between human epididymis protein 4 (HE4) and basal circulating insulin levels. $r=0.16, p=0.064$.

In this study, we wanted to verify if obesity can be considered a risk factor for EOC. Consequently we studied 163 obese patients with BMI greater than $30 \mathrm{~kg} / \mathrm{m}^{2}$ and 130 normalweight women with BMI below $25 \mathrm{~kg} / \mathrm{m}^{2}$. There is literature supporting the evidence that menopausal status is a key factor in the development of EOC, therefore in our study we only included women of premenopausal age to better characterize the role of obesity in the predisposition to EOC (9).

Firstly, we observed a significantly higher percentage of women with high HE4 level in the obese group compared to the normal-weight women. By contrast, in the normal-weight population, we detected a significantly higher percentage with raised levels of CA125 tumor marker. The latter result is in keeping with a previous study that demonstrated a negative correlation between high CA125 concentration and metabolic syndrome (23). However, it is difficult to understand the mechanisms of this negative correspondence because there is lack of literature on the relationship between CA125 level and metabolic syndrome.

Nevertheless, in order to further explore the risk of EOC in obese women, we evaluated the ROMA index in all the women included in this study. A ROMA index $>13 \%$ was identified in $24.5 \%$ of obese patients and in $5.3 \%$ of normal-weight women, therefore classifying these patients at high risk for developing EOC (borderline serous, mucinous and endometrioid cancer) (20). These results let us state that obese patients display an increased risk of EOC onset in comparison with normal-weight women.

On the basis of these results, we hypothesize that in premenopausal women and in particular in obese premenopausal women, it is likely that an excessive secretion of various hormones, growth factors, cytokines, and other mediators may be associated with tumor-initiating cell enrichment, invasiveness and metastasis. 
Remarkably, a recent population-based study that used BMI as a linear effect, after adjusting for several potential confounders, showed that each $5 \mathrm{~kg} / \mathrm{m}^{2}$ increase in BMI was associated with an increased risk of EOC; however, this risk was limited to premenopausal women only $(15,24)$.

Finally, since insulin is one of the most affected hormones in obesity, we investigated if an increase of ROMA index might be related to increased of basal insulin levels in obese patients. The results of our study seem to support our hypothesis: we observed that obese women at high risk of ovarian cancer (ROMA $>13 \%$ ) have higher insulin levels when compared to patients with ROMA $<13 \%$.

Chronic hyperinsulinemia is reportedly related to several risk factors for cancer development $(25,26)$. Although there is no experimental evidence for the positive association between insulin and EOC, some research has shown that increased serum levels of insulin growth factor 1 (IGF1), IGF1 receptor, and IGF-bnding protein 2 (IGFBP2) were positively associated in patients with EOC (27). Other studies have also shown that expression of IGF1 and IGFBP2 in human ovarian cancer cell lines resulted in the induction of proliferation and invasion through AKT and ERK1/2 phosphorylation $(28,29)$.

In this study, we show that insulin might play a role in enhancing the risk of EOC development. After bariatric surgery with normalization of BMI and basal insulin, we observed a fall of ROMA index into the 'healthy' range in $62 \%$ of the obese women previously at high risk of EOC development. Since about $38 \%$ of obese patients did not shown normalization of ROMA index after bariatric surgery nor stabilization of basal insulin level, we hypothesized, in agreement with a previous study, that in addition to insulin, other factors including estrogens, glucocorticoids (18), leptin, adiponectin and inflammatory cytokines could play an important role in the risk for EOC development.

Overall our data suggest that obesity in premenopausal women is a risk factor for EOC. In this setting, the ROMA index might not only be a useful tool to differentiate benign and malignant tumors, but could also be a promising index for use in a possible screening program designed for obese women without pelvic masses. Together with our findings, there seems to be enough evidence to suggest the possible function of the ROMA index as a simple, non-invasive test able to screen obese women at risk of developing EOC for clinicians in the management of obese women.

\section{Acknowledgements}

The Authors are thankful to Valentina Viggiani and Sara Palombi for their technical assistance, to Dr. Flavia Longo, Dr. Sara Tartaglione and Dr. Maria Carla Filippone for helpful comments and discussion, and Dr. Andrea Zivi for his contribution to the English revision of this manuscript.

\section{References}

1 Granato T, Porpora MG, Longo F, Angeloni A, Manganaro L and Anastasi E: HE4 in the differential diagnosis of ovarian masses. Clin Chim Acta 15: 147-155, 2015.

2 Ledermann JA, Raja FA, Fotopoulou C, Gonzalez-Martin A, Colombo N and Sessa C: Newly diagnosed and relapsed epithelial ovarian carcinoma: ESMO Clinical Practice Guidelines for diagnosis, treatment and follow-up. Ann Oncol 24: 24-32, 2013.

3 Colombo N, Peiretti M, Parma G, Lapresa M, Mancari R, Carinelli S, Sessa C and Castiglione M: Newly diagnosed and relapsed epithelial ovarian carcinoma: ESMO Clinical Practice Guidelines for diagnosis, treatment and follow-up. Ann Oncol 21: 23-30, 2010.

4 Sölétormos G, Duffy MJ, Othman Abu Hassan S, Verheijen RH, Tholander B, Bast RC Jr, Gaarenstroom KN, Sturgeon CM, Bonfrer JM, Petersenet TH, Troonen H, Carlo Torre G, Kanty Kulpa J, Tuxen MK and Molina R: Clinical use of cancer biomarkers in epithelial ovarian cancer: Updated guidelines from the European Group on Tumor Markers. Int J Gynecol Cancer 26: 43-51, 2016.

5 Benedet JL, Bender H, Jones H, Ngan HY and Pecorelli S: FIGO staging classification and clinical practice guidelines in the management of gynaecologic cancer. FIGO Committee on Gynaecologic Oncology. Int J Gynaecol Obstet 70: 209-262, 2000.

6 Haries M and Gore M: Part I: chemotherapy for epithelial ovarian cancer-treatment at first diagnosis. Lancet Oncol 3:52936, 2002.

7 Bast RC Jr., Badgwell D, Lu Z, Marquez R, Rosen D, Liu J, Baggerly KA, Atkinson EN, Skates S, Zhang Z, Lokshin A, Menon U, Jacobs I and Lu K: New tumor markers: CA125 and beyond. Int J Gynecol Cancer 15: 274-281, 2005.

8 Chen DX, Schwartz PE, Li XG and Yang Z: Evaluation of CA125 levels in differentiating malignant from benign tumors in patients with pelvic mass. Obstet Gynecol 72: 23-27, 1988.

9 Moore RG, Jabre-Raughley M, Brown AK, Robison KM, Miller MC, Allard WJ, Kurman RJ, Bast RC and Skates SJ: Comparison of a novel multiple marker assay vs. the Risk of Malignancy Index for the prediction of epithelial ovarian cancer in patients with a pelvic mass. Am J Obstet Gynecol 203: 228 e1-6, 2010.

10 Langmár Z, Németh M, Vleskó G, Király M, Hornyák L and Bösze P: HE4-a novel promising serum marker in the diagnosis of ovarian carcinoma. Eur J Gynaecol Oncol 32: 605-610, 2011.

11 Kirchhoff C. Molecular characterization of epididymal proteins. Rev Reprod 3: 86-95, 1998.

12 Clauss A, Lilja $\mathrm{H}$ and Lundwall A: The evolution of a genetic locus encoding small serine proteinase inhibitors. Biochem Biophys Res Commun 9: 333-383, 2005.

13 Kaijser J, Van Belle V, Van Gorp T, Sayasneh A, Vergote I, Bourne T, Van Kalster B and Timmerman D: Prognostic value of serum HE4 Levels and Risk of Ovarian Malignancy Algorithm scores at the time of ovarian cancer diagnosis. Int $\mathrm{J}$ Gynecol Cancer 24: 1173-1180, 2014.

14 Bandiera E, Romani C, Specchia C, Zanotti L, Galli C, Ruggeri G, Tognon G, Bignotti E, Tassi RA, Odicino F, Caini L, Sartori E, Santini AD, Pecorelli S and Ravaggi A: Serum human 
epididymis protein 4 and Risk for Ovarian Malignancy Algorithm as new diagnostic and prognostic tools for epithelial ovarian cancer management. Cancer Epidemiol Biomarkers Prev 20: 2496-2506, 2011.

15 Li K, Hüsing A, Fortner RT, Tjønneland A, Hansen L, Dossus L, Chang-Claude J, Bergmann M, Steffen A, Bamia C, Trichopoulos D, Trichopoulou A, Palli D, Mattiello A, Agnoli C, Tumino R, Onland-Moret NC, Peepers Ph, Bueno-De-Mesquita HB, Gram IT, Weiderpass E, Sanchez-Cantalejo E, Chirlaque MD, Duell EJ, Ardanaz E, Idahl A, Lundin E, Khaw KT, Travis RC, Merritt MA, Gunter MJ, Riboli E, Ferrari P, Terry K, Cramer D and Kaaks R: An epidemiologic risk prediction model for ovarian cancer in Europe: the EPIC study. Br J Cancer 8: 777-785,2015.

16 di Masi A, Leboffe L, De Marinis E, Pagano F, Cicconi L, Rochette-Egly C, Lococo F, Ascenzi P and Nervi C: Retinoic acid receptors: From molecular mechanisms to cancer therapy. Mol Aspects Med 41: 1-115, 2015.

17 Xie J, Poole EM, Terry KL, Fung TT, Rosner BA, Willett WC and Tworoger SS: A prospective cohort study of dietary indices and incidence of epithelial ovarian cancer. J Ovarian Res 7: 112, 2014.

18 Bray GA: The underlying basis for obesity: relationship to cancer. J Nutr 132(11 Suppl): 3451S-3455S, 2002.

19 Health, National Institutes of, Clinical guidelines on the identification, evaluation, and treatment of overweight and obesity in adults - the evidence report, Obes Res 6(Suppl 2): 51S-209S, 1998.

20 Benedetto C, Salvagno F, Canuto EM and Gennarelli G: Obesity and female malignancies. Best Pract Res Clin Obstet Gynaecol 29: 528-540, 2015.

21 Liu Y, Metzinger MN, Lewellen KA, Cripps SN, Carey KD, Harper EI, Shi Z, Tarwater L, Grisoli A, Lee E, Slusarz A, Yang J, Lughran EA, Conley K, Johnson JJ, Klymenko Y, Brumei J, Liang Z, Dovichi NJ, Cheatham B, Leevy WM and Stack MS: Obesity contributes to ovarian cancer metastatic success through increased lipogenesis, enhanced vascularity, and decreased infiltration of M1 macrophages. Cancer Res 1: 5046-5057, 2015.

22 Olsen CM, Green AC, Whiteman DC, Sadeghi S, Kolahdooz F and Webb PM: Obesity and the risk of epithelial ovarian cancer: a systematic review and meta-analysis. Eur J Cancer 43: 690$709,2007$.
23 Joo NS, Kim KN and Kim KS: Serum CA125 concentration has inverse correlation with metabolic syndrome. J Korean Med Sci 26: 1328-1332, 2011.

24 Yang HS, Yoon C, Myung SK and Park SM: Effect of obesity on survival of women with epithelial ovarian cancer: a systematic review and meta-analysis of observational studies. Int J Gynecol Cancer 21: 1525-1532, 2011.

25 Ostman A and Augsten M: Cancer-associated fibroblasts and tumor growth - bystanders turning into key players. Curr Opin Genet Dev 19: 67-73, 2009.

26 Parekh N, Roberts CB, Vadiveloo M, Puvananayagam T, Albu JB and Lu-Yao GL: Lifestyle, anthropometric, and obesityrelated physiologic determinants of insulin-like growth factor 1 in the Third National Health and Nutrition Examination Survey (1988-1994). Ann Epidemiol 20: 182-193, 2010.

27 Beauchamp MC, Yasmeen A, Knafo A and Gotlieb WH: Targeting insulin and insulin-like growth factor pathways in epithelial ovarian cancer. J Oncology doi: 10.1155/2010/257058, 2010.

28 Tanaka Y, Kobayashi H, Suzuki M, Hirashima Y, Kanayama N and Terao T: Genetic down-regulation of pregnancy-associated plasma protein-A (PAPP-A) by bikunin reduces IGF-1 dependent AKT and ERK1/2 activation and subsequently. reduces ovarian cancer cell growth, invasion and metastasis. Int J Cancer 109: 336-347, 2004.

29 Lee EJ, Mircean C, Shmulevich I, Wang H, Liu J, Niemistö A, Kavanagh JJ, Lee JH and Zhang W: Insulin-like growth factorbinding protein 2 promotes ovarian cancer cell invasion. Mol Cancer 4(1): 7, 2005.
Received October 8, 2016

Revised October 26, 2016

Accepted November 9, 2016 